\title{
RE: Concordance of renal stone culture: PMUC, RPUC, RSC and post- PCNL sepsis-a non-randomized prospective observation cohort study
}

\author{
Ibrahim Halil Bozkurt ${ }^{1} \cdot$ Ertugrul Sefik $^{1} \cdot$ Ismail Basmaci $^{1} \cdot$ Serdar Celik $^{1}$
}

Received: 29 March 2018 / Accepted: 18 April 2018 / Published online: 5 May 2018

(c) Springer Science+Business Media B.V., part of Springer Nature 2018

\section{Editor,}

We have read the paper, "Concordance of renal stone culture: PMUC, RPUC, RSC and post-PCNL sepsis-a nonrandomized prospective observation cohort study" [1] with great interest and appreciate the work of the authors. They have tried to determine the association of post PCNL sepsis with preoperative midstream urine cultures (PMUC), renal stone cultures (RSC), and renal pelvic urine culture (RPUC). They found that $24 \%$ had positive culture, $3.2 \%$ (4/122) PMUC, $14.7 \%$ (18/122) RPUC, and 13.9\% (17/122) RSC. Seven patients (5.7\%) developed postoperative infectious complications.

We have a few queries.

The authors stated that single-dose third generation cephalosporin was used for prophylaxis. We have read from the paper of Lojanapiwat et al. [2] stating that the bacteria isolated from patients with sepsis revealed more resistance to ceftriaxone, ceftazidime, quinolones, and amoklavin-klavulonik asit, while being relatively more sensitive to amikacin, ampicillin, vancomycin, and carbapenem. And these results guided the authors to rearrange the antibiotics used in the prophylaxis. The antibiogram of the positive cultures were given as multisensitive and multiresistant in the recent paper. We kindly ask the authors what percent of these cultures were third generation cephalosporin resistant? And does it have any impact on anticipating infectious complications in the current study?

In the case of infectious complications, two aerobic hemocultures in addition to a new PMUC were obtained from each patient. The results of hemocultures were not given in results section. We think that it is very important data. How many of the patients had positive hemocultures and does it have concordance with PMUC, RPUC, or SC?

Stone-free rate was reported as $68.4 \%$ for staghorn stones and $85.0 \%$ for for non-staghorn stones. In the case of residual stones with positive stone culture what was the approach of the authors? Is it a risk factor for postoperative infectious complication?

\section{Compliance with ethical standards}

Conflict of interest Ibrahim Halil Bozkurt, Ismail Basmaci, Ertugrul Sefik, and Serdar Celik declares that they have no conflict of interest.

\section{References}

1. Walton-Diaz A, Vinay JI, Barahona J et al (2017) Concordance of renal stone culture: PMUC, RPUC, RSC and post-PCNL sepsis-a non-randomized prospective observation cohort study. Int Urol Nephrol 49:31-35

2. Lojanapiwat B, Kitirattrakarn P (2011) Role of preoperative and intraoperative factors in mediating infection complication following percutaneous nephrolithotomy. Urol Int 86:448-452
Ibrahim Halil Bozkurt

ihalilbozkurt@yahoo.com

$1 \quad$ HSU Izmir Bozyaka Training and Research Hospital Urology Clinic, Saim Cikrikci Str. No:59, Karabaglar, Izmir, Turkey 